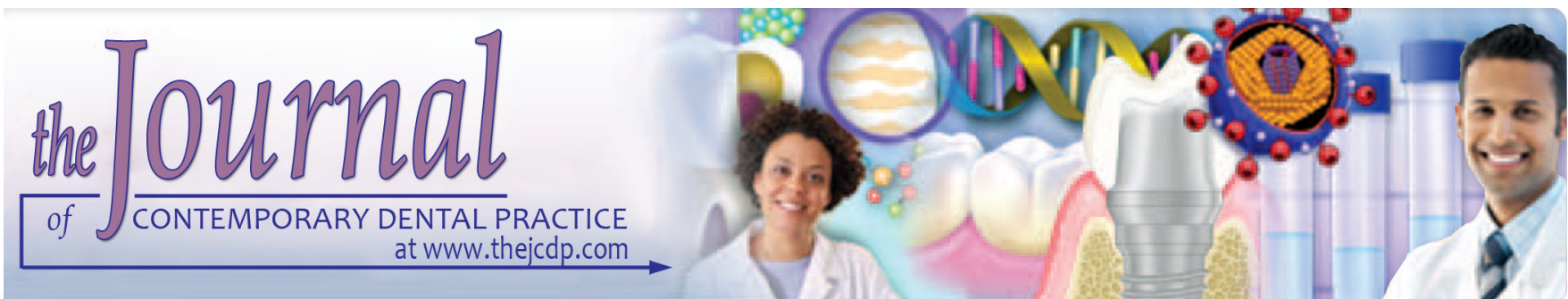

\title{
Comparative Clinical Evaluation of Composite Overcast Gold Post and Core Buildups in Endodontically Treated Teeth
}

\author{
${ }^{1}$ Swapna Munaga, ${ }^{2}$ Abhisek Das, ${ }^{3}$ Tamanpreet Kaur, ${ }^{4}$ Ashfaq Yaqoob, ${ }^{5}$ Rizwan Mokashi, ${ }^{6}$ Prabhu MS Ismail
}

\begin{abstract}
Background: The management of non-vital teeth includes endodontic treatment and restoration followed by post and core restoration in selected cases. The present study was conducted to compare the indirect cast post, and core buildup with direct composite post build up in patients.
\end{abstract}

Materials and Methods: The present study was conducted on 128 teeth of 82 patients. The success rate over 3 years was evaluated clinically and radiographically by observing caries, tooth mobility, probing depth, periapical pathology, and root fractures.

Results: Group I consisted of 16 incisors, 20 canines, 22 premolars, and six molars while group II had 17 incisors, 14 canines, 25 premolars, and eight molars. The difference was statistical non-significant ( $p-0.1)$. Forty-four teeth in group I and 42 teeth in group II utilized composite cement, whereas 18 teeth in group I and 16 teeth in group II used GIC and zinc phosphate was used in two teeth in group I and six teeth in group II. The difference was statistical ly significant $(p<0.05)$. Four teeth in group I and 8 in group II were lost. One tooth in

\footnotetext{
${ }^{1}$ Department of Conservative Dentistry and Endodontics, Qaseem Private Colleges, Buraydah, Kingdom of Saudi Arabia

${ }^{2}$ Department of Conservative Dentistry, HiTech Dental College, Bhubaneswar, Odisha, India

${ }^{3}$ Department of Conservative Dentistry and Endodontics, Swami Devi Dayal Dental College and Hospital, Barwala, Panchkula, Haryana, India

${ }^{4}$ Department of Prosthodontics, College of Dentistry, King Khalid University, Abha, Kingdom of Saudi Arabia

${ }^{5}$ Department of Conservative Dentistry and Endodontic, SMBT Dental College, Nashik, Maharastra, India

${ }^{6}$ Department of Conservative Dentistry, College of Dentistry at Al Rass, Qassim University, Kingdom of Saudi Arabia

Corresponding Author: Swapna Munaga, Department of Conservative Dentistry and Endodontics, Qaseem Private Colleges, Buraydah, Kingdom of Saudi Arabia e-mail : swapnamunga@gmail.com
}

group I and two teeth in group II showed root fracture and three teeth in group I and six teeth in group II showed periapical pathology. The difference was statistically significant ( $p-0.01)$. Most common type of complication was probing depth $>4 \mathrm{~mm}$, caries, tooth mobility, and root fracture. The difference was non- significant $(p-0.31)$.

Conclusion: Both composite post buildup and cast gold post and core build-up exhibited similar properties.

Clinical significance: Both composite post buildup and cast gold post and core build-up exhibited similar properties hence either of the methods can be used in post core build up.

Keywords: Composite, Core, Gold, Post

How to cite this article: Munaga S, Das A, Kaur T, Yaqoob A, Mokashi R, Ismail PMS. Comparative Clinical Evaluation of Composite Overcast Gold Post and Core Buildups in Endodontically Treated Teeth. The Journal of Contemporary Dental Practice, October 2018;19(10):1273-1277.

Source of support: Nil

Conflict of interest: None

\section{INTRODUCTION}

The main cause of tooth loss is caries, fracture, etc. The carious tooth can be managed with the restoration using different restorative materials available today. The purpose of any restoration is to maintain the vitality and function of the tooth. Restorative materials such as glass ionomer cement (GIC) and silver amalgam are commonly used in the dentistry. With the introduction of composites and light cure GIC, the management of carious tooth has become easier and effective. ${ }^{1}$

Fracture due to trauma is another frequent reason requiring restoration. The part of tooth lost due to trauma is build up with GIC, or composite, etc. The requirement of the crown over tooth depends upon the type of fracture. Fracture limited to enamel or dentin can be managed while those involving pulp demand endodontic treatment 
followed by crown placement. In case of excessive tooth loss, post-build-up becomes necessary. ${ }^{2}$

The post is inserted into the root, and it provides support to the restorative material placed over it. Considering the physical, and chemical properties similar to that of dentin, various materials such as glass ionomer, gold, zirconia have been used since past. Materials such as composite, ceramic, amalgam, etc. are widely used restorative materials for core build up. It is the part of restoration which is attached to the post and provides support to the tooth. ${ }^{3}$

The success of any restoration is judged by the survival rate and complications arising from it in the future. Post and core restoration which fulfills the esthetics and function is considered to be successful. Those with frequent complaints or complications are in the category of failure. ${ }^{4}$ The present study was done to evaluate and compare clinically the success rate of indirect cast post and core buildups with direct composite post build up in endodontically treated teeth.

\section{MATERIALS AND METHODS}

The present study was conducted in the Department of Conservative Dentistry and Endodontics after obtaining ethical clearance from the institutional ethical committee and informed consent from all the participating subjects . The study comprised of 128 composite or cast post and core build-up in 82 patients of both genders.

Patients were divided into two groups of 64 samples in each group. Group I were those who received composite (titanium post) core build up and group II received cast (gold post) core build up. General information such as name, age, gender, etc. was noted in case history Performa.

Endodontic treatment in the indicated teeth was done and teeth were obturated using gutta-percha by the lateral condensation technique. Post space was prepared by removing gutta-percha using peeso reamer and leaving 4-5 mm of apical gutta-percha. Cementation of either composite post or gold post core was done using dual-cure adhesive cement after treating post space with a chelating agent (Glyde, Germany). Core build-up was done to a height of $4 \mathrm{~mm}$ using a composite material in group I.

All patients were recalled for 3 years for follow-up visits. During each visit, all patients were questioned about any lost teeth in the past and examined clinically and radiographically (intraoral periapical radiographsIOPAR) to checks its success. Clinical examination was performed to record caries, tooth mobility and probing depth $(\mathrm{mm})$. The presence or absence of periapical radiolucency or root fracture was assessed with IOPA radiographs. Two independent dentists analyzed the cases to eliminate the intra-observer bias. Average of observer's findings was considered for statistical analysis using SPSS Statistics for Windows, Version 19.0. Armonk, NY: IBM Corp and with chi-square and Fisher exact test. The $p$-value of less than 0.05 was considered significant.

\section{RESULTS}

Table 1 shows that out of 82 patients, males were 30 and females were 52 . The difference was significant (P- 0.02). Table 2 shows that group I (64) had 16 incisors, 20 canines, 22 premolars, and six molars while group II (64) had 17 incisors, 14 canines, 25 premolars, and eight molars. The difference was statistica lly non- significant ( $p-0.1)$. Graph 1 shows that type of cement used was composite (group I-44, group II-42), GIC (group I-18, group II-16) and zinc phosphate (group I-2, group II-6). The difference was statistical ly significant $(\mathrm{p}<0.05)$. Table 3 shows that out of 12 teeth lost, four were in group I and 8 were in group II. The difference was statistically significant $(p<0.05)$. Type of reconstruction was single crown (group I-1, group II-2), splinted crown (group I-1, group II-1) and fixed partial denture (FPD) (group I-2, group II-5) (p-0.01). The

Table 1: Distribution of patients

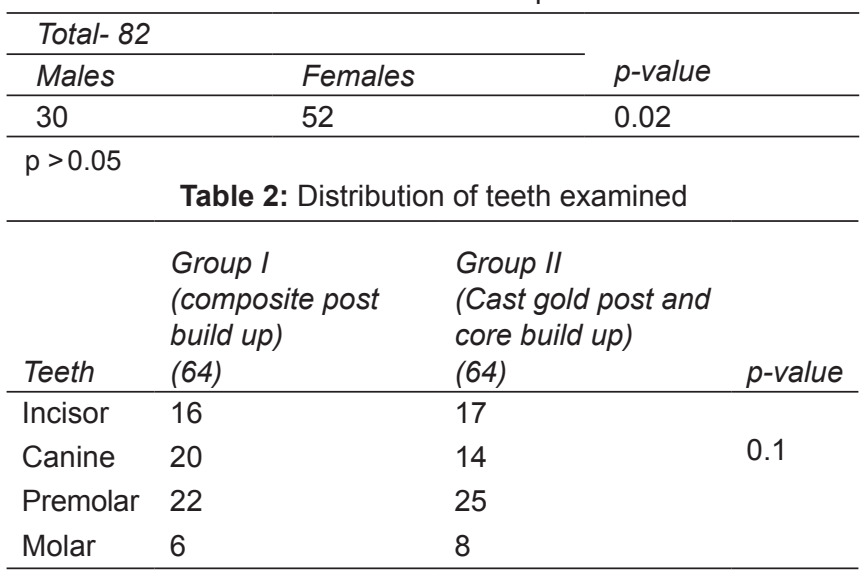

$p<0.05$

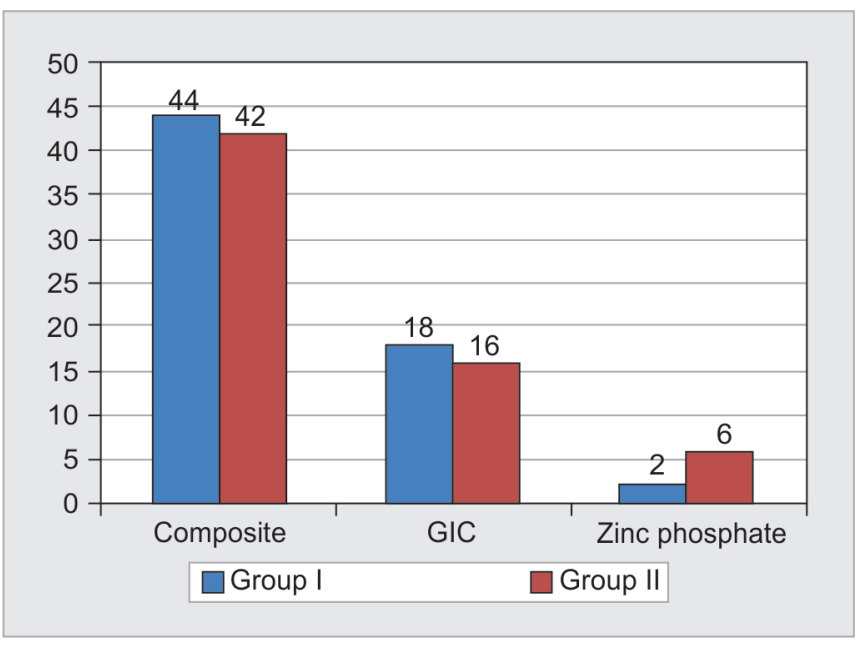

Graph 1: Type of cement used in study 
Table 3: Teeth loss in both groups

\begin{tabular}{lllll}
\hline Characteristics & & Group I & Group II & $p$-value \\
\hline Teeth lost & Single crown & 1 & 8 & 0.001 \\
Type of & $\begin{array}{l}\text { Splinted } \\
\text { crown }\end{array}$ & 1 & 1 & 0.5 \\
reconstruction & & & 1 \\
& FPD & 2 & 5 & 0.01 \\
$\begin{array}{l}\text { Reason of } \\
\text { extraction }\end{array}$ & $\begin{array}{l}\text { Root fracture } \\
\text { Periapical }\end{array}$ & 1 & 2 & 0.5 \\
& pathology & & 6 & 0.01 \\
\hline
\end{tabular}

$p>0.01$

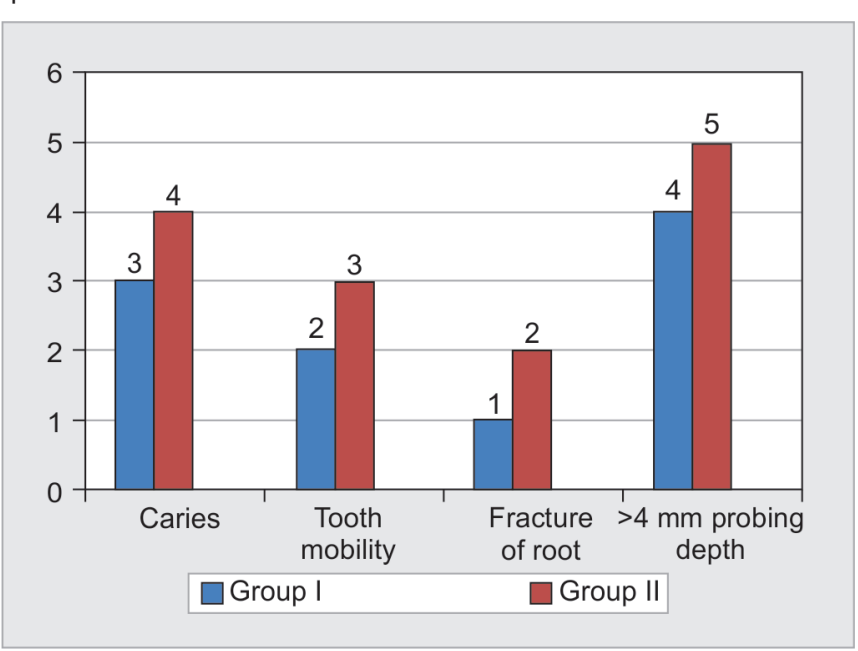

Graph 2: Type of complications in both groups

reason for extraction was root fracture (group I-1, group II-2) and periapical pathology (group I-3, group II-6). The difference was statistically significant ( $\mathrm{p}-0.01)$. Graph 2 shows that most common type of complication was probing depth $>4 \mathrm{~mm}$ (group I-4, group II-5) followed by caries (group I-3, group II-4), tooth mobility (group I-2, group II-3) and root fracture (group I-1, group II-2). The difference was non-significant $(\mathrm{p}-0.31)$.

\section{DISCUSSION}

In the era of dentistry management of non-vital teeth has no more complicated. Earlier pulpless teeth were considered for extraction. With endodontic treatment, the ability to retain the natural teeth still persists. Endodontic treatment followed by post-placement enhances the success rate of pulpless teeth. An ideal post should be able to withstand the occlusal forces, the ability to adapt to variously shaped canals, demands less tooth removal. It should be biologically compatible with physical properties similar to that of dentin. ${ }^{5}$

Nowadays, glass fibers posts, quartz fiber posts, and zirconia posts have been widely used. All have advantages and a few disadvantages. These posts provide adequate retention and resistance. Their ability to withstand the occlusal forces and resistance to corrosion has made them popularized among dentists. ${ }^{6}$
In the present study, we compared composite post and core build-up with indirect gold post and core build up. In this study, we included 128 tee th of 82 patients. Composite posts found to be better than gold posts. The use of prefabricated posts and composite resin cores started in the late $60 \mathrm{~s}^{7}$ The fiber content, nature of the matrix and flexural strength has additional advantages of the composite post and core build up. Akayan et $a l^{8}$ in their study, evaluated resistance to fracture of endodontically treated teeth restored with different post systems, and they found composite to be superior to other posts. There has been a transition from metal custom-cast posts and cores to prefabricated metal posts and resinbased composite cores, especially in the last few years.

The ability of a post to remain in the root canal is the key factor for the success of the treatment. They should have sufficient tensile bonds to prevent separation. ${ }^{9}$ The retention should be adequate to avoid failure. In our study, zinc phosphate cement was used in two teeth in group I and six teeth in group II. One of the most significant advantages of this cement is that it has the long-term high success rate. The disadvantage is lack of adhesion to the tooth. Solubility is another drawback.

Creugers et al. ${ }^{10}$ in their study of a meta-analysis of durability data on conventional fixed bridges observed that composite resins cement have better biomechanical properties and more resistant to fractures. However, Bachicha et al. ${ }^{11}$ in their study found that microleakage of endodontically treated teeth restored with posts using resin cement have limited role in narrow canals, have technically high sensitivity.

Kimmel SS et al. evaluated the reinforcement of endodontically treated teeth with a polyethylene ribbon and prefabricated fiberglass post and found that composite resins have higher adhesive shrinkage and viscosity. ${ }^{12}$ Titanium posts used in group I in the present study is a prefabricated metal post which provides extensive strength to the unit. Cast gold cores made from reinforced direct wax and direct acrylic resin patterns have been suggested. Gold alloys have a better coefficient of thermal expansion. They are preferred over several posts as they possess the adequate compressive strength to withstand masticatory forces. Type III or IV cast gold alloys have a modulus of elasticity almost similar to enamel.

It has been observed form earlier studies that cast gold resistance to leakage is der ived from the luting agent and doesn't absorb water and has a coefficient of thermal expansion (CTE) very close to that of dentin. ${ }^{13}$ Zicari et al. and Jung et al. found similar clinical performance with glass fiber post with composite core overcast gold posts and core whereas Khaledi et al. observed significantly 
higher fracture resistance of the teeth restored with Nickel-Chromium (Ni-Cr) post and core system than Non-Precious Gold alloy (NPG group). ${ }^{14-16}$ Bittner et al. concluded from their study that mean failure load was comparatively lower in custom cast gold post compared to fiber/zirconia post. ${ }^{17}$ Martinez-Insua et al. in their study reported higher fracture loads with cast gold than carbon fiber. ${ }^{18}$ Schwartz RS and Robbins form review of literature observed relatively lower survival rate with a cast post and gold types. ${ }^{19}$

Microleakage is an important factor in the success of cemented post-core system to endodontically treated teeth. Microleakage is related to the solubility of cement or marginal deboning between the restorative material and tooth structure. Cementation of the post-core system can be done with self-cure, light cure or dual-cure cement. ${ }^{20}$

In the present study, the common complication was probing depth $>4 \mathrm{~mm}$, caries, increased tooth mobility, and root fracture. We found that probing depth $>4 \mathrm{~mm}$ was seen in four teeth in group I and five in group II.

Similarly, caries was observed in three teeth in group I, and four in group II, two teeth in group I and three in group II showed increased tooth mobility whereas one in group I and two in group II exhibited root fractures. The prevalence of root fracture found to be high with gold posts. Moreover, it has poor esthetics. However, titanium post used in group I showed one case of root fracture. They possess low fracture strength. Fernandez ${ }^{21}$ in his review article of factors determining post selection suggested that titanium posts have a density similar to that of gutta-percha hence are difficult to differentiate it radiographically.

Mentnik et al. ${ }^{22}$ in their study entitled survival rate and failure characteristics of all metal post and core restorations found $7.5 \%$ of failure rates in 516 posts. Valderhaug et al. ${ }^{23}$ observed $20 \%$ failures after 10 years of retrospective study on 106 custom made posts in 397 patients. Hatzikyriakos et al. ${ }^{24}$ found $9.1 \%$ failure rate in 44 custom made posts. Heydecke G. ${ }^{25}$ in his systematic review of the restoration of endodontically treated singlerooted teeth with cast or direct posts and cores suggested that lower success rate of composite core build-up may be due to the presence of more number of screws.

Bateman $\mathrm{G}$ et $a .^{26}$ in their study of fiber-based post systems found a composite post and core better than GIC and zinc phosphate. Microleakage was the main drawback associated with GIC and zinc phosphate. Freeman et al. ${ }^{27}$ their study of leakage associated with load fatigue-induced preliminary failure of full crowns placed over three different post and core systems found that microleakage and caries development in composite build ups is due to its ability to absorb moisture.

\section{CONCLUSION}

Post and core are widely used in cases of non-vital endodontic treated teeth. Most common complications observed were root fracture, increased probing depth, mobility, caries and periapical pathology. Both groups exhibited almost similar properties. We found more failure rate (4) in group I compared to group-II (8). Our results indicated that cast post with composite has a better success rate overcast gold post-core.

\section{REFERENCES}

1. Robbins WJ. Restoration of the endodontically treated tooth. Dent Clin N Am 2002; 46:367-384.

2. William Cheung A review of the management of endodontically treated teeth. JADA 2005; 136:611-620.

3. Rolf KC, Parker MW, Pelleu GB. Stress analysis of five prefabricated endodontic dowel designs: a photoelastic study. Oper Dent1992;17:86-92.

4. Deutsch, Musikant BL, Cavallari J, and Lepley JB. Prefabricated dowels: A literature review. JPD 1983;49:498504.

5. Cheung W. A review of the management of endodontically treated teeth Post, core and the final restoration. JADA. 2005;136:611-619

6. Hoag EP, Dwyer TG. A comparative evaluation of three post and core techniques. J Prosthet Dent 1982; 47:177-181.

7. Kvist T, Rydin E,Reit C. The relative frequency of periapical lesions in teeth with root canal retained posts. J Endod 1989; 15:578-580.

8. Akkayan B, Gulmez T. Resistance to fracture of endodontically treated teeth restored with different post systems. J Prosthet Dent 2002;87:431-437.

9. Sorensen JA, Engelman MJ. Effect of post adaptation on fracture resistance of endodontically treated teeth. J Prosthet Dent 1990; 64:419-424.

10. Creugers NHJ, Mentink AGM, Fokkinga WA, Kreulen CM. 5 -year follow-up of a prospective clinical study on various types of core restorations.lnt J Prosthodont 2005;18:34-39.

11. Bachicha WS, DiFiore PM, Miller DA, Lautenschlager EP, Pashley DH. Microleakage of endodontically treated teeth restored with posts. J Endod 1998;24:703-770.

12. Kimmel SS. Restoration and reinforcement of endodontically treated teeth with a polyethylene ribbon and prefabricated fiberglass post. Gen Dent. 2000; 6:700-6.

13. Alex McLean. Predictably Restoring Endodontically Treated Teeth. J Can Dent Assoc 1998;64:782-787

14. Zicari F, Van Meerbeek B, Debels E, Lesaffre E, Naert I.An up to 3-Year Controlled Clinical Trial Comparing the Outcome of Glass Fiber Posts and Composite Cores with Gold Alloy-Based Posts and Cores for the Restoration of Endodontically Treated Teeth. Int J Prosthodont. 2011 Jul-Aug;24(4):363-72.

15. Jung RE, Kalkstein O, Sailer I, Roos M, Hämmerle CH. A comparison of composite post buildups and cast gold postand-core buildups for the restoration of nonvital teeth after 5 to 10 years. Int J Prosthodont. 2007 Jan-Feb;20(1):63-9.

16. Khaledi AAR, Sheykhian S, Khodaei A. Evaluation of Retention of two Different Cast Post-Core Systems and Fracture Resistance of the Restored Teeth. J Dent (Shiraz). 2015 Jun; 16(2):121-128. 
17. Bittner N, Hill T, Randi A.Evaluation of a one-piece milled zirconia post and core with different post-andcore systems: An in vitro study. The Journal of Prosthetic Dentistry. 2010;103(6):369-379

18. Martinez-Insua A, da Silva L, Rilo B, Santana U. Comparison of the fracture resistances of pulpless teeth restored with a cast post and core or carbon-fiber post with a composite core. J Prosthet Dent 1998;80:527-32.

19. Schwartz RS, Robbins JW. Post Placement and Restoration of Endodontically Treated Teeth: A Literature Review. Journal of Endodontics. 2004;30(5):289-301

20. Bergali CD, de Carvallo RF, Balducci I, Meira IB, de Araujo MAM, Valera MC. Influence of fiber post cementation length on coronal microleakage values in vitro and finite element analysis. J Cont Dent Pract. 2014;15(4):444-450

21. Fernandes AS, Shetty S, and Coutinho I. Factors determining post selection: A literature review. JPD 2003;90:556-62.

22. Mentink AGB, Creugers NHJ, Meeuwissen R. Leempoel PJB. Kayser AF. Clinical performance of different post and core systems-Results of a pilot study. J Oral Rehabil 1993;20:577-584.

23. Valderhaug J, Jokstad A, Ambjørnsen E, Norheim PW. Assessment of Periapical clinical status of crowned teeth over 25 years. Journal of dentistry 1997;25:97-105.

24. Hatzikyriakos AH, Reisis GI. Tsingos N.A 3-year postoperative clinical evaluation of posts and cores beneath existing crowns. J Prosthet Dent 1992;67:454458.

25. Heydecke G, Peters MC. The restoration of endodontically treated single-rooted teeth with cast or direct posts and cores: A systematic review. J Prosthet Dent 2002;87:380386.

26. Bateman G, Ricketts DN, Saunders WB. Fibre-based post systems: A review. Br Dent J 2003; 195:43-48.

27. Freeman MA, Nicholls JI, Kydd WL, Harrington Gw. Leakage associated with load fatigue-induced preliminary failure of full crowns placed over three different post and core systems. J Endod 1998;24:26-32. 